\title{
Long-Term Preservation by Freeze-Drying of Pathogenic Bacteria of the Czechoslovak National Collection of Type Cultures
}

\author{
JIŘI ŠOUREK \\ Institute of Hygiene and Epidemiology, Prague, Czechoslovakia
}

\begin{abstract}
On the basis of long-term experience with the preservation of the pathogenic bacteria of the Czechoslovak National Collection of Type Cultures, it is concluded that the suspending medium is a factor of primary importance in the preservation of these organisms in the freeze-dried state. The primary index of suspending medium effectiveness is the level of protection it affords against the adverse effects of low (subzero) temperatures, dehydration, long-term storage, and rehydration. A number of simple and compound suspending media were studied for their protective effects on cultures from over 50 genera of predominantly pathogenic bacteria. The results indicate that not only each bacterial genus and species but also frequently every strain of a given serological type must be looked upon as a distinct biological entity, the preservation of the viability, activity, and desirable characters of which must be tested in different protective media in preliminary experiments. Heat testing (at 75 to $100 \mathrm{C}$ ) of freeze-dried cultures kept under high vacuum is recommended as a good indicator of adequate protection provided by a suspending medium. With the freeze-drying technique used, the best results for the largest number of species were obtained with a mixture of calf serum or defibrinated sheep blood and lactose solution (to a final concentration of 5 to $10 \%$ ) and Annear's peptone-containing medium. Individual suspending media were evaluated in relation to individual strains, and recommendations are made as to the preferred medium on the basis of control tests performed at 5-, 10-, and 15-year intervals.
\end{abstract}

Twenty-five years have elapsed since the establishment of the Czechoslovak National Collection of Type Cultures (CNCTC) at the Institute of Epidemiology and Microbiology (in 1971, the Institute of Epidemiology and Microbiology became a part of the newly established Institute of Hygiene and Epidemiology under the name Center of Epidemiology and Microbiology). At present, the CNCTC contains over 7,000 strains of bacteria, viruses, and fungi, the majority of which have been successfully preserved by the relatively modern method of freeze-drying, first employed at the CNCTC in 1948. The freeze-drying technique has made important headway both in Czechoslovakia and abroad (16), the continuing refinement of this technique having proceeded along the lines of improvements in the freeze-drying apparatus (19) and in the suspending media used for freeze-drying $(1,4,6,7,9,10,12,20,21)$.

A number of laboratories have recently summarized their long experience with freezedrying as applied to the preservation of microorganisms $(3,5,9,10,17)$ and by so doing have provided valuable information for culture collections and other laboratories interested in microorganism preservation. We present our experience on the preservation of the pathogenic bacteria maintained and stored at the CNCTC and of various recently isolated bacteria maintained at the National Reference Laboratories of the Institute of Hygiene and Epidemiology (22).

\section{MATERIALS AND METHODS}

Bacterial strains. The results reported here are based on the strains listed in the CNCTC Catalogue of 1969 (22), containing over 50 genera and over 130 species, and on a number of strains isolated from clinical or other material at the laboratories of the Center of Epidemiology and Microbiology and at the Department of Tuberculosis Microbiology of the Institute of Hygiene and Epidemiology.

Culture media. Prior to freeze-drying, cells were grown on solid agar bases (not diagnostic or selective) that afforded optimal growth. Exceptions were as follows: Haemophilus influenzae, which was cultivated for 24 to $48 \mathrm{~h}$ in broth enriched with a $0.5 \%$ yeast 
extract (Difco) and defibrinated sheep blood (15 drops per $5 \mathrm{ml}$ of broth); Streptococcus pyogenes, cells of which were grown in Todd-Hewitt broth for 16 to $18 \mathrm{~h}$, centrifuged, and resuspended in calf serum (peptone broth was used for the standard strains employed in the production of streptolysin $\mathrm{O}$ ); and Actinomyces israelii, which was grown in liver broth.

Preservation procedure. The preservation procedure consisted basically of the following steps: (i) homogenization of the bacterial culture in the suspending medium; (ii) freezing of the suspension in dry ice; (iii) dehydration of the frozen suspension; (iv) sealing of ampoules under vacuum; (v) purity and viability assays; (vi) storage of ampoules under constant conditions.

The bacterial cells were normally homogenized either in 2 or 3 drops of suspending medium pipetted into small ampoules or in a large quantity of suspending medium, small volumes of which were then distributed into small ampoules. These ampoules were stoppered with cotton plugs. Any other procedures used are described directly in connection with the cultures concerned. A system of double ampoules was employed, the internal (small) ampoule being 6 by 40 $\mathrm{mm}$ in size and the external (large) one being 9 by 180 $\mathrm{mm}$.

Freezing was most often performed directly in dry ice $(-78.5 \mathrm{C})$, with a mean temperature drop of 1 $\mathrm{C} / 10$ s. In special cases (Francisella tularensis and Yersinia pestis), freezing was accomplished in an alcohol bath adjusted to the desired temperature with dry ice $(-10,-20 \mathrm{C}$, etc.). The freezing period lasted $45 \mathrm{~min}$. In certain instances (as with Vibrio cholerae, Neisseria gonorrhoeae, and Clostridium perfringens), the cultures were dried from the liquid rather than the frozen state.

The method of freeze-drying used was one easily accessible to most laboratories. The simple freezedrying device consists of a vacuum desiccator and a vacuum pump with an effect of $10^{-2}$ to $10^{-3}$ torr. In addition, a special freeze-drying apparatus (model "Lyovar T" Secfroid, Lausanne, Switzerland) was employed in those cases where it was necessary to avoid the thawing of the frozen culture at the start of the drying process (as was the case when peptone and high sugar concentrations were used). Cultures were dried by the batch method, the ampoules being placed in a container. Bubbling of the suspending medium was prevented by using a specially adjusted perspex chamber as the container (diamater $14 \mathrm{~cm}$, height 14 $\mathrm{cm}$ ) which was cooled at the beginning of freezedrying for a period of 1 to $2 \mathrm{~h}$ with dry ice placed in an aluminum box beneath the chamber.

When cultures were dried without freezing, the drying was performed in a desiccator initially by using a suction and pressure pump giving a normal vacuum better than 60 torr for 2 to $3 \mathrm{~h}$, and then by using a vacuum pump giving $10^{-2}$ torr for 3 to $5 \mathrm{~h}$.

In these cases, the ampoules were kept overnight in the desiccator in the presence of fresh $\mathrm{P}_{2} \mathrm{O}_{5}$ under vacuum.

The day after the drying, the small ampoules containing the dried cultures and moisture indicators (filter paper strips impregnated with a $3 \% \mathrm{CoCl}_{2}$ solution and dried in streaming air) were placed in the outer ampoules which, after constriction and 15 to 25 min of air evacuation, were sealed under vacuum by flaming. The tips of the ampoules were immersed in a special wax "Microcer IMP II" (a refined mixture of solid paraffin and isoparaffin hydrocarbons, produced by Chemický Závod, Żidlochovice u Brna, Czechoslovakia) which forms a "cap" that protects the thin tips of the ampoules against damage. When evacuation was performed without freezing, or when the "Lyovar T" apparatus was used for freeze-drying, the cultures were dried on the first day for 5 to $6 \mathrm{~h}$ and then again on the second day for 7 or $8 \mathrm{~h}$. The ampoules were sealed in the same manner as above on the third day.

The freeze-dried cultures were checked for purity and viability after 1 or 2 weeks by seeding, after rehydration with broth, onto nutrient agar and into an appropriate liquid medium provided that the filter paper strips had remained blue in the unopened ampoules, an indication that the ampoules contained no leaks.

The ampoules were stored at laboratory, or any cooler, temperature (preferably $4 \mathrm{C}$ ) in the dark.

Suspending media. The following media, affording varying degrees of protection for different organisms, were used to suspend the cells for freeze-drying.

Medium 1. Medium 1 consisted of normal clear calf serum inactivated at $56 \mathrm{C}$ in a water bath for $45 \mathrm{~min}$. Our first freeze-dryings were performed with equine or bovine serum.

Medium 2. Medium 2 was calf serum plus lactose: after sterilization at $100 \mathrm{C}$ (in running steam for 20 min on 3 consecutive days), a $10 \%$ ( $\mathrm{L} 10$ ) or $20 \%$ ( $\mathrm{L}$ 20) lactose solution in distilled water was diluted with an equal volume of calf serum. Four percent of gelatin was added when freeze-drying $H$. influenzae.

Medium 3. Medium 3 was defibrinated sheep blood plus lactose: a $10 \%$ sterile solution of lactose with $2 \%$ gelatin in distilled water was mixed with an equal volume of blood.

Medium 4. Medium 4 consisted of skim milk (Dif co): a $10 \%$ solution of skim milk in distilled water ( $\mathrm{pH}$ adjusted to 7.3 to 7.4 ) was sterilized at $100 \mathrm{C}$ in running steam for $20 \mathrm{~min}$ on 3 consecutive days.

Medium 5. Medium 5 was modified Annear's medium (1): $6 \%$ peptone, $0.5 \%$ soluble starch, $1 \%$ sodium glutamate, and $1 \%$ gelatin dissolved in hot distilled water. The $\mathrm{pH}$ was adjusted to 7.2 to 7.4 , and the medium was sterilized in the autoclave $(120 \mathrm{C}$ for $20 \mathrm{~min}$ ).

Medium 6. Medium 6 was sucrose plus gelatin: a mixture of $10 \%$ sucrose and $1 \%$ gelatin was dissolved in distilled water. The $\mathrm{pH}$ was adjusted to 7.2 to 7.4 , and the medium was autoclaved $(120 \mathrm{C}$ for $20 \mathrm{~min})$.

Medium 7. Medium 7 consisted of cystein $\mathrm{HCl}$ $(0.5 \%)$ plus tryptophan $(0.1 \%)$ plus lactose $(0.5 \%)$. These were dissolved in physiological saline, the $\mathrm{pH}$ was adjusted to 7.2 to 7.4 , and the medium was sterilized in running steam $(20 \mathrm{~min}$ on 3 consecutive days).

Medium 8. Medium 8 was Naylor medium (12), consisting of dextrin (2\%), ammonium chloride $(0.5 \%)$, and thiourea $(0.5 \%)$, dissolved in physiologic saline. After adjusting the $\mathrm{pH}(7.2$ to 7.4$)$ and autoclaving, a sterile solution of $0.5 \%$ ascorbic acid was added under aseptic conditions. In some cases the 
medium was modified in that dextrin was replaced by lactose $(2 \%)$. Sometimes 5 drops of $0.1 \%$ methylene blue (as redox indicator) were added per $5 \mathrm{ml}$ of this medium.

Control tests included experiments to study the effect of various substances on the viability of freeze-dried organisms. These substances were, e.g., different concentrations of glycerin, dextran $(6 \%)$, potato extract with glycerin, or a solution of starch $(2 \%)$ in saline with veronal buffer.

All suspending media were divided into suitable volumes (ca. $3 \mathrm{ml}$ ) and then sterilized and stored in the refrigerator as long as they remained clear and without any apparent change (ca. 2 to 3 months).

Heat tests. The protective effect of the suspending medium on the freeze-dried organisms was checked at temperatures of 75 and $100 \mathrm{C}$, as a rule within 1 or 2 weeks after freeze-drying. The freeze-dried cultures (under vacuum) were heated for $30 \mathrm{~min}$ in a water bath. The moisture indicator was checked before and after the heating; if dehydration was complete, the indicator did not change color. After cooling the ampoules to laboratory temperature, the cultures were tested for purity and viability in the usual manner.

\section{RESULTS}

Freeze-drying in the suspending media studied confirmed that the protective effects of proteins (serum, blood), carbohydrates (lactose, sucrose, starch), and their mixtures present a heterogeneous pattern. Microorganisms freezedried under standard conditions displayed, when tested at intervals of 1,3 , and 6 months and $1,2,3,4$, and 5 years, etc., growth of varying degree depending on the suspending medium employed. Often two or more media produced an equivalent protective effect, but it also frequently happened that only one medium preserved a particular characteristic of the strain, such as pigment formation (Serratia) or motility (Proteus), or favored a particular growth form, e.g., the $\mathrm{M}$ form (Klebsiella) or $\mathrm{S}$ form (Salmonella), etc. Other markers were the intensity of primary culture growth on nutrient agar and colony size and shape in relation to cell morphology and biochemical and serological properties of the culture. Some of the original properties which had partially been suppressed or activities that had been retarded by the freeze-drying could be revived to their normal values on repeated subculture. Our results with freeze-drying pathogenic and some other medically relevant bacteria as gradually obtained in the course of 26 years are summarized in Table 1. The names of the organisms are listed alphabetically by genus and species. (The nomenclature used is that found in Bergey's Manual of Determinative Bacteriology, 1957; in the case of the more recently described taxa, the nomenclature is that pro- posed in the International Journal of Systematic Bacteriology.)

Diplococcus pneumoniae. Thus far the types most highly sensitive to freeze drying have been $6 \mathrm{~B}, 7 \mathrm{C}, 14,15,17 \mathrm{~A}, 18,22$, and 35 . The suspending medium was individually tested for these types in preliminary experiments, including heat tests as indicators of protection. We recommend cultivation of $M$ forms on tryptic soy agar with the addition of $10 \%$ of defibrinated sheep blood. It has become clear that another critical factor is rehydration; Todd-Hewitt broth is the most suitable growth medium for revival.

Haemophilus influenzae. Optimal growth obtained after 24 to $48 \mathrm{~h}$ of cultivation in enriched broth. After resuspending the blood cells, the culture was placed in small ampoules and mixed with an equal volume of suspending medium enriched with $4 \%$ of gelatin. Positive growth after the heat test at $100 \mathrm{C}$ was obtained only from cultures grown in peptone (medium 5). Haemophili are highly sensitive to residual moisture, and therefore the humidity indicator must remain blue throughout storage.

Mycobacterium tuberculosis, M. bovis, M. microti, M. avium, and atypical fast-growing mycobacteria (photochromogens, scotochromogens, and nonchromogens). These organisms have no special requirements for freeze-drying, as shown by viability tests after 12 to 16 years of storage of cultures that had been suspended merely in a water solution of $1 \%$ sodium glutamate. The cultures retained their characteristic features. Decreased growth was obtained with skim milk (medium 4), starch, serum, and peptone (medium 5); a number of strains gave very poor growth in Löwenstein medium. Growth studies in Šula liquid medium showed that skim milk (4), lactose plus serum (2), and lactose plus blood (3) support pellicle formation even in strains normally growing only in a sediment. Cultures freeze-dried with sheep blood, dextran, or glycerin generally produced turbid growth when revived; this particularly applies to the mammalian mycobacteria. Atypical mycobacteria fully retained their pigmentation intensity and colony morphology. Data on these items will be published in greater detail separately.

Streptococcus pyogenes. This microorganism possesses a broad spectrum of biologically active substances whose preservation frequently requires a special freeze-drying procedure. Although good results have been obtained with freeze-drying some types in serum alone (medium 1), in that growth was obtained even 
TABLE 1. Viability of freeze-dried bacteria from the Czechoslovak National Collection of Type Cultures

\begin{tabular}{|c|c|c|c|c|}
\hline Name of organism & $\begin{array}{l}\text { No. of } \\
\text { strains }^{a}\end{array}$ & $\begin{array}{l}\text { Sus- } \\
\text { pending } \\
\text { medium }\end{array}$ & $\begin{array}{l}\text { Survival } \\
\text { in years } b\end{array}$ & Comments \\
\hline Acinetobacter calcoaceticus & 10 & 4 & 8 & $\begin{array}{l}\text { Former synonyms: Bacterium ani- } \\
\text { tratum, Herellea spp., Mima poly- } \\
\text { morpha }\end{array}$ \\
\hline Actinomyces israelii & 14 & 1 & 9 & \\
\hline Aeromonas hydrophila & 1 & 4 & 8 & \\
\hline A. salmonicida & 1 & 4 & 8 & \\
\hline A. shigelloides & 2 & 4 & 8 & \\
\hline Alcaligenes bookeri & 1 & $2 \mathrm{~L} 10$ & 12 & \\
\hline A. faecalis & 1 & $2 \mathrm{~L} 10$ & 12 & \\
\hline A. marshalii & 1 & $2 \mathrm{~L} 10$ & 6 & \\
\hline A. odorans & 2 & $2 \mathrm{~L} 10$ & 10 & \\
\hline Arizona sp. & 35 & $2 \mathrm{~L} 10$ & 15 & \\
\hline Bacillus anthracis & 16 & 1 & 23 & \\
\hline B. cereus & 12 & 1 & 15 & \\
\hline B. megaterium & 4 & 1 & 17 & \\
\hline B. pumilus & 1 & 1 & 8 & \\
\hline B. stearothermophilus & 1 & 1 & 9 & \\
\hline B. subtilis & 20 & 1 & 17 & \\
\hline Bordetella bronchiseptica & 5 & $2 \mathrm{~L} 10$ & 12 & Media 4 and 5-variable growth; \\
\hline B. parapertussis & 7 & $2 \mathrm{~L} 10$ & 13 & only cultures from medium 5 \\
\hline B. pertussis & 19 & $2 \mathrm{~L} 10$ & $13)$ & provided viability in heat test \\
\hline Brucella abortus & 40 & $2 \mathrm{~L} 10$ & $17)$ & Good growth provided by medium \\
\hline B. melitensis & 4 & $2 \mathrm{Ll} 0$ & $15\}$ & 3 and serum-enriched potato \\
\hline B. suis & 5 & $2 \mathrm{~L} 10$ & 12 & extract \\
\hline Citrobacter freundii & 104 & $2 \mathrm{~L} 10$ & 15 & \\
\hline Clostridium bifermentans & 1 & 1 & 10 & \\
\hline C. botulinum & 14 & 1 & 12 & \\
\hline C. histolyticum & 4 & 1 & 10 & \\
\hline C. novyi & 3 & 1 & 10 & \\
\hline C. perfringens & 20 & 3 & 8 & Dehydration without freezing \\
\hline C. septicum & 5 & 1 & 10 & \\
\hline C. sporogenes & 6 & 1 & 17 & \\
\hline C. tetani & 4 & 1 & 16 & \\
\hline Corynebacterium acnes & 2 & $2 \mathrm{~L} 10$ & 14 & \\
\hline C. cutis & 1 & 1 & 7 & \\
\hline C. diphtheriae & 31 & 1 & 23 & \\
\hline C. equi & 2 & 1 & 10 & \\
\hline C. haemolyticum & 6 & 1 & 14 & \\
\hline C. murium & 1 & 1 & 3 & \\
\hline C. pseudodiphtheriticum & 4 & 1 & 20 & \\
\hline C. pseudotuberculosis & 5 & 1 & 12 & \\
\hline C. pyogenes & 9 & 1 & 15 & \\
\hline C. renale & 1 & 1 & 3 & \\
\hline C. striatum & 1 & 1 & 10 & \\
\hline C. ulcerans & 3 & 1 & 11 & \\
\hline C. xerosis & 1 & 1 & 3 & \\
\hline Diplococcus pneumoniae & 86 & $\begin{array}{l}5,2 \mathrm{~L} 10, \\
\mathrm{~L} 20\end{array}$ & 11 & See text \\
\hline Edwardsiella tarda & 3 & $2 \mathrm{~L} 10$ & 7 & \\
\hline Enterobacter aerogenes & 8 & $2 \mathrm{~L} 10$ & 11 & \\
\hline E. cloacae & 13 & $2 \mathrm{~L} 10$ & 11 & \\
\hline E. hafniae & 9 & $2 \mathrm{~L} 10$ & 10 & \\
\hline Erysipelothrix insidiosa & 7 & 1 & 17 & \\
\hline Erwinia sp. & 1 & $2 \mathrm{~L} 10$ & 15 & \\
\hline Escherichia coli & 284 & 5 & 15 & $\begin{array}{l}\text { Medium } 7 \text { has also shown good } \\
\text { protective properties }\end{array}$ \\
\hline
\end{tabular}


TABLE 1.-Continued

\begin{tabular}{|c|c|c|c|c|}
\hline Name of organism & $\begin{array}{l}\text { No. of } \\
\text { strains }\end{array}$ & $\begin{array}{l}\text { Sus- } \\
\text { pending } \\
\text { medium }\end{array}$ & $\begin{array}{l}\text { Survival } \\
\text { in years } b\end{array}$ & Comments \\
\hline $\begin{array}{l}\text { Flavobacterium spp. } \\
\text { Francisella tularensis }\end{array}$ & $\begin{array}{l}2 \\
7\end{array}$ & $\begin{array}{l}2 \mathrm{~L} 10 \\
6\end{array}$ & $\begin{array}{r}14 \\
6\end{array}$ & $\begin{array}{l}\text { Freezing should not exceed } \\
-20 \mathrm{C} \text {; virulence tests not } \\
\text { performed }\end{array}$ \\
\hline Gaffkya tetragena & 2 & $2 \mathrm{~L} 10$ & 17 & \\
\hline Haemophilus haemolyticus & 1 & $2 \mathrm{~L} 10$ & 10 & \\
\hline H. influenzae & 10 & $2 \mathrm{L10}$ & 11 & See text \\
\hline H. parainfluenzae & 1 & $2 \mathrm{L10}$ & 10 & \\
\hline Klebsiella ozaenae & 12 & $2 \mathrm{~L} 10$ & 12 & Media 4,5 or carbohydrate so- \\
\hline$K$. pneumoniae & 85 & $2 \mathrm{~L} 10$ & 15 & lutions-variable growth; only \\
\hline$K$. rhinoscleromatis & 19 & $2 \mathrm{~L} 10$ & 12 & $\begin{array}{l}\text { cultures from medium } 5 \text { provided } \\
\text { viability in heat test }\end{array}$ \\
\hline Kurthia zopfii & 1 & 1 & 16 & \\
\hline Leuconostoc mesenteroides & 1 & 3 & 7 & \\
\hline Listeria monocytogenes & 34 & 1 & 20 & \\
\hline Micrococcus flavus & 4 & 1 & 15 & \\
\hline M. lysodeikticus & 1 & 1 & 10 & \\
\hline Moraxella lacunata & 4 & $2 \mathrm{~L} 10$ & 9 & \\
\hline Mycobacterium spp. & 95 & $2 \mathrm{~L} 10$ & 16 & See text \\
\hline Mycoplasma pneumoniae & 2 & PPLO broth & 8 & $\begin{array}{l}\text { 7- to 10-day-old cultures in } \\
\text { PPLO broth enriched with } 0.5 \% \\
\text { of yeast extract and } 20 \% \text { of } \\
\text { horse serum were freeze-dried } \\
\text { directly in this medium }\end{array}$ \\
\hline Neisseria catarrhalis & 1 & $2 \mathrm{~L} 10$ & 6 & \\
\hline N. flavescens & 2 & 4 & 8 & \\
\hline N. gonorrhoeae & 23 & 3 & 6 & Dehydration without freezing \\
\hline N. meningitidis & 44 & $2 \mathrm{L10}$ & 10 & \\
\hline N. mucosa & 4 & $2 \mathrm{~L} 10$ & 10 & \\
\hline Nocardia asteroides & 1 & 4 & 8 & \\
\hline N. madurae & 1 & 4 & 12 & \\
\hline N. rubra & 1 & 4 & 8 & \\
\hline Pasteurella haemolytica & 6 & $2 \mathrm{~L} 10$ & 3 & \\
\hline P. multocida & 25 & $2 \mathrm{~L} 10$ & 17 & $\begin{array}{l}\text { Only cultures from medium } 5 \\
\text { provided viability in heat test }\end{array}$ \\
\hline P. pneumotropica & 2 & $2 \mathrm{~L} 10$ & 3 & \\
\hline Pediococcus cerevisiae & 1 & 1 & 8 & \\
\hline Proteus hauseri & 76 & 5 & 15 & Minor deviations in growth in \\
\hline P. morganii & 35 & 5 & 15 & heat test when using medium 2 , \\
\hline$P$. rettgeri & 42 & 5 & 15 & starch or serum alone \\
\hline Providencia spp. & 34 & 5 & 15 & \\
\hline Pseudomonas aeruginosa & 70 & $2 \mathrm{~L} 10$ & 15 & Enhancement of protective \\
\hline P. indoloxidans & 1 & $2 \mathrm{~L} 10$ & 7 & - effect by lactose in any \\
\hline Pseudomonas spp. & 5 & $2 \mathrm{~L} 10$ & 15 & combination \\
\hline Salmonella spp. & 522 & $2 \mathrm{~L} 10$ & 15 & \\
\hline Serratia indica & 3 & $2 \mathrm{~L} 10$ & $9)$ & Media 2 and 4 are better than \\
\hline S. marcescens & 18 & $2 \mathrm{~L} 10$ & $14\}$ & 8, but medium 8 with dextrin \\
\hline S. plymuthica & 3 & $2 \mathrm{~L} 10$ & $9)$ & $\begin{array}{l}\text { replaced by lactose and methyl- } \\
\text { ene blue favors pigment forma- } \\
\text { tion }\end{array}$ \\
\hline Shigella arabinotarda & 16 & $2 \mathrm{~L} 10$ & 15 & \\
\hline S. boydii & 30 & $2 \mathrm{~L} 10$ & 15 & \\
\hline$S$. dysenteriae & 29 & $2 \mathrm{~L} 10$ & 15 & \\
\hline S. flexneri & 60 & $2 \mathrm{~L} 10$ & 15 & \\
\hline S. schmitzii & 19 & $2 \mathrm{L10}$ & 15 & \\
\hline S. sonnei & 33 & $2 \mathrm{L10}$ & 15 & \\
\hline S. spp. & 13 & $2 \mathrm{~L} 10$ & 8 & \\
\hline Staphylococcus aureus & 84 & 1 & 23 & \\
\hline S. epidermidis & 7 & 1 & 20 & \\
\hline Streptococcus spp. & 493 & 1 & 23 & See text \\
\hline
\end{tabular}


TABLE 1.-Continued

\begin{tabular}{|c|c|c|c|c|}
\hline Name of organism & $\begin{array}{l}\text { No. of } \\
\text { strains }^{a}\end{array}$ & $\begin{array}{l}\text { Sus- } \\
\text { pending } \\
\text { medium }\end{array}$ & $\begin{array}{l}\text { Survival } \\
\text { in years } b\end{array}$ & Comments \\
\hline Streptomyces albus & 3 & 4 & 10 & \\
\hline$S$. griseus & 3 & 4 & 10 & \\
\hline Veillonella spp. & 2 & 3 & 1 & $\begin{array}{l}\text { Strains under study; } 48-\mathrm{h} \\
\text { cultivation after Fortner }\end{array}$ \\
\hline Vibrio alginolyticus & 1 & 3 & 3 & \\
\hline$V$. cholerae & 26 & 3 & 17 & Dehydration without freezing \\
\hline Vibrio NAG & 4 & 4 & 5 & \\
\hline$V$. parahaemolyticus & 2 & 3 & 3 & \\
\hline Yersinia enterocolitica & 35 & $2 \mathrm{~L} 10$ & 5 & \\
\hline$Y$. pestis (avirulent) & 2 & 6 & 6 & $\begin{array}{l}\text { Freezing should not exceed } \\
-20 \mathrm{C} \text {; cultivation on McCoy } \\
\text { egg medium }\end{array}$ \\
\hline Y. pseudotuberculosis & 20 & $2 \mathrm{~L} 10$ & 13 & \\
\hline
\end{tabular}

${ }^{a}$ The table only lists the strains given in the Catalogue of Pathogenic Microorganisms of the CNCTC. On the basis of the experience gained in freeze-drying these strains, further large collections of cultures (e.g., Bordetella, Escherichia, Mycobacterium, Neisseria, Pseudomonas, Salmonella, Shigella, Staphylococcus, Streptococcus, Vibrio, and Yersinia) isolated from clinical material in other laboratories of the Center of Epidemiology and Microbiology were freeze-dried.

${ }^{b}$ The figures given do not represent mean values but interim values of culture viability. The different figures thus reflect the various times at which freeze-drying of the respective organisms was started. Previously, either the freeze-drying attempts had not been satisfactory (e.g., inadequate suspending medium had been used, as in the cases of Escherichia, Haemophilus, Pseudomonas, Salmonella, Shigella) or the cultures had not been available to the CNCTC.

after more than 20 years, it appears that both bovine and equine sera contain a certain quantity of antistreptolysis $O$, which appreciably reduces streptolysin $O$ production, and may also contain undeterminable amounts of some antibiotics (9). To fully preserve the ability of streptolysin $\mathrm{O}$ production, our procedure consists of cultivation in Todd-Hewitt broth and resuspension of the sediment after centrifugation in calf serum (strains from clinical material) or peptone (streptolysin $O$ producers). Where the objective is to preserve a special property of the strain (e.g., "minute," MG, etc.), it is preferable to use certain other suspending media, such as $2, \mathrm{~L} 10$, or 3 . $\mathrm{M}$-antigen preservation has been successfully effected as follows: a 4- to 5-h-old culture grown in Todd-Hewitt broth enriched with $20 \%$ of calf serum was frozen as usual and directly freeze-dried in small amounts. Control tests carried out after 7 years have so far been highly satisfactory.

A somewhat different mode of freeze-drying has been chosen for $\mathbf{L}$ forms in view of their fragility. A 4-day-old broth culture (brain heart infusion [Difco], enriched with yeast extract or tryptic soy broth, either medium supplemented with $10 \%$ of calf serum for tissue cultures and several antibiotics) is distributed in 1-ml volumes into ampoules, frozen, and freeze-dried (Lyovar T). Viability of freeze-dried L-forms has so far been reliably verified after 5 years of storage.

\section{DISCUSSION}

It is our opinion that the suspending medium is the most important factor in preserving the viability and biological activity of freeze-dried cultures. Animal serum, previously employed as the "most suitable" medium, has manifested a number of nonspecific detrimental effects on viability in the course of time. To date, efforts to find a "universal" medium for all pathogens have failed $(1,9,10)$. The question of the protective effects of different suspending media has long been the subject of study, and the results reported here have reaffirmed that different suspending media provide varying degrees of protection for different microorganisms. Preliminary experiments, including heat tests, are helpful in establishing the optimal protection medium, especially for highly fragile strains or for strains on which there is little information on their preservation.

The basic criteria for determining the protective value of any suspending medium can be summed up as follows: (i) protection against the effect of low temperature $(-78.5 \mathrm{C}$ to -200 C) during rapid prefreezing; (ii) protection against dehydration effects (during slow 
drying); (iii) protection against high-temperature effects under high vacuum in relation to residual moisture; and (iv) protection against the effects of rehydration. The protective effect is expressed in terms of the partial properties of each individual component of the suspending medium, namely, solubility and stability in solution, rapid dehydration under vacuum without liquefaction, ready solubility at reconstitution of dry matter, and the antioxidant equilibrium (23). Maximal solubility of the individual components and their stability in the solution insure, together with the soluble substances of the microbial cells, that a film of colloidal material forms around the cells, protecting them against the unfavorable influences of the various external changes that occur in the course of freezing, drying, and possibly storage (15). The choice of suspending medium is a matter of much consequence, and, in bacteria with certain labile properties of interest, preliminary experimentation is indicated.

In freeze-drying a grown culture which was previously freeze-dried, a decision must be made as to whether an identical or a different suspending medium will be used. Our experience to date has been very good using the same medium as initially employed; however, much more experience must be gained before the use of a different medium in subsequent freezedryings can be evaluated. If the primary culture grown after the rehydration displays all the desirable properties, the subsequent freezedrying is performed directly from this culture; otherwise the culture is first subjected to at least one cycle of growth.

In the course of the freeze-drying (or drying) process, some occurrences may markedly influence culture viability and must be avoided or immediately counteracted. At the beginning of drying and later during evacuation, the bacterial suspension must not dissolve (or bubble in drying). If dehydration is done properly, one may observe drying taking place progressively from the suspension surface downward; a color change is also noticeable. The formation of dry matter all along the small ampoule in the form of a glossy film or its accumulation in the cotton-wool plug is, as a rule, a sign of improper dehydration. Good results are only obtained when the dried suspension is deposited at the bottom of the ampoule in the shape of a "plug."

Dehydration is considered to be most efficient if carried out for the shortest possible time, for it avoids the untoward effects that occur during slow dehydration (16). Only if a culture is freeze-dried in a Lyovar T apparatus (freezing applied from below) or is merely dried (without freezing) is it recommended to carry on the evacuation to the next day and seal the culture on the third day.

The humidity indicator should not change color after sealing the ampoule. A color change signifies either that the residual moisture has increased (above $2 \%$ ) or that the ampoule has been mechanically damaged (most probably at the seal).

In rehydrating freeze-dried cultures, it is preferable to use broth rather than physiologic saline or distilled water despite dissolving being more rapid in the latter two media. The use of broth has given very good results in experiments carried out in our laboratory, and our results are in good agreement with the findings of other authors (20). Viability tests should be performed at various time intervals.

Our long-term experience has shown that data relating to the suitability of suspending media for cultures maintained in collections are generally also valid for freshly isolated cultures in their first or second passage. This statement is based on information supplied by the National Reference Laboratories for Streptococcus, Salmonella, Shigella, Staphylococcus, Bordetella, Haemophilus, and others (Mycoplasma, Neisseria, Yersinia, Vibrio) of the Institute of Hygiene and Epidemiology.

\section{ACKNOWLEDGMENTS}

I thank the workers of the Czechoslovak National Collection of Type Cultures, R. Bergmannová, S. Kuldová, J. Mašková, and V. Tomášková, for their outstanding technical assistance; I am indebted to members of the different National Reference Laboratories, in particular J. Jelínková and J. Śrámek (Streptococcus), E. Aldova (Shigella, Vibrio), M. Bruckov' (Mycoplasma, Yersinia pestis, Francisella tularensis), B. Vysoká (Bordetella), M. Kubín, M. Ślosárek, and Z. Miková (Mycobacterium), for valuable comments.

\section{REPRINT REQUESTS}

Address reprint requests to: Dr. Jiři Šourek, Center of Epidemiology and Microbiology, Institute of Hygiene and Epidemiology, 10042 Praha 10, Šrobárova 48, Czechoslovakia.

\section{LITERATURE CITED}

1. Annear, D. I. 1956. The preservation of bacteria by drying in peptone plugs. J. Hyg. 54:487-508. 2. Berge, T. O., R. L. Jewett, and W. O. Blair. 1971. 
Preservation of enteroviruses by freeze-drying. Appl. Microbiol. 22:850-853.

3. Berman, S., P. L. Altieri, A. Groffinger, and J. P. Lowenthal. 1966. Freeze-drying various strains of Shigella. Appl. Microbiol. 16:1779-1781.

4. Garvie, E. I. 1967. Preservation of Vibrio fetus by freeze drying. J. Appl. Bacteriol. 30:255-260.

5. Gore, L. F. 1970. Storage of freeze-dried cultures. Lab. Pract. 19:923.

6. Hopwood, D. A., and H. M. Ferguson. 1969. A rapid method for lyophilizing Streptomyces cultures. J. Appl. Bacteriol. 32:434-436.

7. Hoštálek, Z. 1957. The Maintenance of Eremothecium ashbyi. J. Gen. Microbiol. 17:267-273.

8. Jung, M., and U. Krech. 1971. Lyophilization of human cytomegalovirus. Pathol. Microbiol. 37:47-56.

9. Lapage, S. P., J. E. Shelton, and T. G. Mitchell. 1970. Media for the maintenance and preservation of bacteria, p. 1-134. In J. R. Norris and D. W. Ribbons (ed.). Methods in microbiology, vol. $3 \mathrm{~A}$. Academic Press Inc., London.

10. Lapage, S. P., J. E. Shelton, T. G. Mitchell, and A. R. Mackenzie. 1970. Culture collections and the preservation of bacteria, p. 135-288, In J. R. Norris and D. W. Ribbons (ed.). Methods in Microbiology, vol. 3A. Academic Press Inc., London.

11. Leach, R. H., and W. J. Scott. 1959. The influence of rehydration on the viability of dried micro-organisms. J. Gen. Microbiol. 21:295-307.

12. Naylor, H. B., and P. A. Smith. 1946. Factors affecting the viability of Serratia marcescens during dehydration and storage. J. Bacteriol. 52:565-573.

13. Norman, M. C., E. B. Franck, and R. V. Choate. 1970. Preservation of Mycoplasma strains by freezing in liquid nitrogen and by lyophilization with sucrose. Appl. Microbiol. 20:69-77.

14. Protocala, R., I. Samuel, and M. Popescu. 1969. Effect of lyophilization on Picornaviruses. Arch. Gesamte Virsuforsch. 28:97-99.

15. Record, B. R., and R. Taylor. 1953. Some factors influencing the survival of Bacterium coli on freeze-drying. J. Gen. Microbiol. 9:475-484.

16. Rey, L. 1964. Aspects théoretiques et industriels de la lyophilisation. Hermann-Paris.

17. Rhoades, H. E. 1970. Effects of 20 years storage on lyophilized cultures of bacteria, molds, viruses and yeasts. Amer. J. Vet. Res. 31:1867-1871.

18. Richards, M., and F. R. Elliott. 1968. Freezedrying characteristics of Saccharomyces cerevisiae and $S$. carlsbergensis. Antonie von Leewenhoek J. Microbiol. Serol. 34:227-233.

19. Rowe, T. W. G. 1960 . The theory and practice of freeze-drying. Ann. N.Y. Acad. Sci. 85:641-679.

20. Seastone, C. V. 1971. Viability of lyophilized streptococci. J. Infect. Dis. 124:619.

21. Servin-Massieu, K., and R. Cruz-Camarillo. 1969. Variants of Serratia marcescens induced by freeze-drying. Appl. Microbiol. 18:689-691.

22. Šourek, J. 1969. Catalogue of pathogenic microorganisms. Prague.

23. van Drimmelen, G. C., and H. S. Steyn. 1958. The keeping quality of freeze-dried Brucella abortus strain 19 vaccine. J. Gen. Microbiol. 19:324-329. 